\title{
Removal of Arsenic (III, V) from aqueous solution by nanoscale zero-valent iron stabilized with starch and carboxymethyl cellulose
}

\author{
Mohammad Mosaferi ${ }^{1,2}$, Sepideh Nemati ${ }^{3 *}$, Alireza Khataee ${ }^{4}$, Simin Nasseri ${ }^{2}$ and Ahmad Asl Hashemi ${ }^{5}$
}

\begin{abstract}
In this work, synthetic nanoscale zerovalent iron (NZVI) stabilized with two polymers, Starch and Carboxymethyl cellulose (CMC) were examined and compared for their ability in removing As (III) and As (V) from aqueous solutions as the most promising iron nanoparticles form for arsenic removal.

Batch operations were conducted with different process parameters such as contact time, nanoparticles concentration, initial arsenic concentration and $\mathrm{pH}$.

Results revealed that starch stabilized particles (S-nZVI) presented an outstanding ability to remove both arsenate and arsenite and displayed 36.5\% greater removal for As (V) and 30\% for As (III) in comparison with CMC-stabilized nanoparticles (C-nZVI). However, from the particle stabilization viewpoint, there is a clear trade off to choosing the best stabilized nanoparticles form. Removal efficiency was enhanced with increasing the contact time and iron loading but reduced with increasing initial As (III, V) concentrations and pH. Almost complete removal of arsenic (up to $500 \mu \mathrm{g} / \mathrm{L}$ ) was achieved in just 5 min when the S-nZVI mass concentration was $0.3 \mathrm{~g} / \mathrm{L}$ and initial solution $\mathrm{pH}$ of $7 \pm 0.1$. The maximum removal efficiency of both arsenic species was obtained at $\mathrm{pH}=5 \pm 0.1$ and starched nanoparticles was effective in slightly acidic and natural $\mathrm{pH}$ values. The adsorption kinetics fitted well with pseudo-second-order model and the adsorption data obeyed the Langmuir equation with a maximum adsorption capacity of $14 \mathrm{mg} / \mathrm{g}$ for arsenic (V), and $12.2 \mathrm{mg} / \mathrm{g}$ for arsenic (III).

It could be concluded that starch stabilized Fe nanoparticles showed remarkable potential for As (III, V) removal from aqueous solution e.g. contaminated water.
\end{abstract}

Keywords: Metallic iron, Nanoparticles, Water purification, Arsenic, Adsorption

\section{Introduction}

Arsenic, a notorious poison, is now recognized to be one of the world's greatest environmental hazards, threatening the lives of several hundred million people [1]. In many areas of the world, biogeochemical processes have resulted in a release of naturally occurring As into groundwater; in some cases, large regions are affected [2]. On the other hand, uncontrolled anthropogenic activities such as (mining, fossil fuels burning, smelting of metal ores, and use of wood preservatives, pesticides and arsenic additives to livestock feed) may also release arsenic directly to the environment [3-5]. As a result exposure to arsenic

\footnotetext{
* Correspondence: Nemati.sepid@gmail.com

${ }^{3}$ Department of Environmental Health Engineering, School of Health, Center of Student Researches, Tabriz University of Medical Sciences, Tabriz, Iran Full list of author information is available at the end of the article
}

compounds is a major concern to public health in both developing and developed countries [6] and removal of arsenic from drinking water is a worldwide priority.

Exposure to elevated arsenic levels has been attributed to adverse health related issues such as changes in skin pigmentation, diabetes, lung ailments, and cancers of the kidney and bladder [7]. Due to its significant toxicity, the World Health Organization has established a value of $10 \mu \mathrm{g} \mathrm{As} / \mathrm{L}$ as the maximum contaminant level for total As in potable water [8].

In Iran, the occurrence of geogenic arsenic in some of rural areas in Kurdistan province, located in the West of country is responsible for health problems related to chronic As exposure from drinking water [9]. Arsenic contamination of drinking water has also been detected in Hashtrud county, in the Northwest of the country [10] 
and Kohsorkh area in the Northeast of Iran [11] where arsenic concentration in water is higher than the National Iranian Drinking Water Standard, $10 \mu \mathrm{g}$ As/L [12]. Therefore, it is an urgent need to provide Arsenic free drinking water in the mentioned areas.

As well known, arsenic exists in the natural environment mainly in the forms of arsenite [As (III)] and arsenate [As $(\mathrm{V})]$. Arsenite is more mobile and toxic than arsenate and most removal technologies are efficient when the element is presented in the pentavalent state $[13,14]$.

Removal of arsenic contamination from water can be accomplished by a variety of techniques such as coagulation $[15,16]$, adsorption $[17,18]$, ion exchange [19], membrane filtration [20,21] and biological process [22].

A significant problem encountered in the removal of arsenic from groundwater aquifers and municipal water systems is the presence of arsenic in both arsenic states arsenic (III) and arsenic (V). Arsenic (III) compounds are primarily non-ionic whereas arsenic (V) compounds are ionic at natural water $\mathrm{pH}$ [23].

In comparison with other removal methods, zero-valent iron (ZVI, $\mathrm{Fe}^{0}$ ) can simultaneously remove As (V) and As (III) without previous oxidative treatment and does not require the use of additional chemical products, since metallic iron is used for the sustained production of colloidal hydrous ferric oxides (HFO) [14]. ZVI reactions are rather slow, but the process can be notably accelerated using iron nanoparticles (NZVI) [24]. Due to the low amount of nano or micro zero-valent iron used, the mass of the sludge produced in the process is significantly low; so, the flocs may be removed by magnetic techniques, often more efficient and faster than centrifugation or filtration [25].

Despite these advantages, $\mathrm{Fe}^{0}$ nanoparticles were found to be lack in stability in water and in the absence of an effective stabilizer, aggregate rapidly (in a few minutes), resulting in micro-, millimeter-scale or even larger aggregates [26,27].

Aggregation and sedimentation can significantly alter the mobility of the nanoparticles in aquatic environment and reduce the efficacy of using these nanoparticles for remediation purposes $[28,29]$.

Surface modification of NZVI by polyelectrolytes, polymers and surfactants, which provide steric and electrostatic stabilization against the particle-particle attractive forces, significantly improves its transport in porous media [30].

Among all reported stabilizers, water soluble polysaccharides have been proved to be the best stabilizer due to their low cost and environmental compatibility [31]. So, it seems that green polysaccharides such as starch and Carboxymethyl cellulose $(\mathrm{CMC})$ can be used as effective protecting agents to enhance the reactivity of iron nanoparticles.

Starch is a nontoxic, biodegradable and inexpensive biopolymer. Recent study by Alidokht et al. [32] indicated that application of starch as the stabilization agent prevents the aggregation of $\mathrm{Fe}^{0}$ nanoparticles which causes high $\mathrm{Cr}$ (VI) removal efficiency in comparison with nonstabilized NZVI.

CMC is a chemical derivative of cellulose and has carboxylate groups in addition to hydroxyls, which may result in strong interaction between CMC and Fe nanoparticles [31]. CMC is also a food-grade ingredient, nontoxic and biodegradable and this is likely due to the presence of highly biodegradable $-\mathrm{OH},-\mathrm{CO}-$, and $-\mathrm{COOH}$ groups [33].

$\mathrm{Xu}$ and Zhao [34] test the feasibility of using the CMC-stabilized ZVI nanoparticles for in situ reductive immobilization of $\mathrm{Cr}$ (VI) in contaminated water and soils and reported these nanoparticles may serve as a highly soil-dispersible and effective agent for immobilization of chromate.

To the best of our knowledge, the improved removal of arsenic using starch and CMC stabilized zerovalent iron nanoparticles has not yet been reported in details. Keeping in view the high toxicity of arsenic and high capability of polymer stabilized NZVI in removal of various pollutants; the present study investigates the performance of these nanoparticles in removing arsenic species from aqueous solutions for the first time. Since the mechanism of arsenic removal using stabilized NZVI remains unclear, the possible interaction between arsenic and two stabilized NZVI was proposed. The specific aims were: (1) synthesis and characterization of stabilized $\mathrm{Fe}^{0}$ nanoparticles; (2) comparison removal efficiency of As (III) and As (V) by starch stabilized nZVI (S-nZVI), CMC stabilized nZVI (C-nZVI) and bare nanoparticles; and (3) determining the effects of environmental factors on the removal ability of selected form of nanoparticles.

\section{Experimental \\ Materials}

All chemicals were of reagent grade. Ferrous sulfate heptahydrate $\left(\mathrm{FeSO}_{4} \cdot 7 \mathrm{H}_{2} \mathrm{O}\right)$, Sodium borohydride $\left(\mathrm{NaBH}_{4}\right)$, Sodium arsenite stock solution $\left(\mathrm{NaAsO}_{2}, 0.05 \mathrm{~mol} / \mathrm{L}\right)$ were purchased from (Merck Co, Germany). As (V) stock solution $(100 \mathrm{mg} / \mathrm{L})$ was prepared from $\mathrm{Na}_{2} \mathrm{HAsO}_{4} \cdot 7 \mathrm{H}_{2} \mathrm{O}$ (GIFT Co) and stored at $4^{\circ} \mathrm{C}$. Water soluble starch and sodium carboxymethyl cellulose, (CMC 90 k) were obtained from Fluka and Sigma (UK) Co respectively. The chemical reagents were used directly without further purification.

\section{Synthesis of nanoparticles}

Nano-Fe ${ }^{0}$ particles were synthesized using the borohydride method [35]. A key advantage of this method is its simplicity. It can be safely done in most chemistry lab with simple chemical reagents. Conventionally these nanoparticles can be synthesized by both $\mathrm{FeSO}_{4} \cdot 7 \mathrm{H}_{2} \mathrm{O}$ and $\mathrm{FeCl}_{3} \cdot 6 \mathrm{H}_{2} \mathrm{O}$ but during the reaction with the borohydride solution, these 
two different aqueous solution salts show significant and stoichiometrical differences in reaction. Borohydride reacts more rapidly with $\mathrm{FeSO}_{4} \cdot 7 \mathrm{H}_{2} \mathrm{O}$ than $\mathrm{FeCl}_{3} \cdot 6 \mathrm{H}_{2} \mathrm{O}$, which is important because it tends to be less oxidized in the solution obtained after synthesis and may save time [36]. For this reason $\mathrm{FeSO}_{4}$ is better option for NZVI synthesis.

For preparation of starch-stabilized $\mathrm{Fe}^{0}$ nanoparticles, first an aqueous solution of $0.14 \mathrm{M} \mathrm{FeSO}_{4} \cdot 7 \mathrm{H}_{2} \mathrm{O}(100 \mathrm{ml})$ and $0.2 \%(\mathrm{w} / \mathrm{w})$ starch as a stabilizer were stirred with an electric rod in a $500 \mathrm{ml}$ three necked round bottom flask for $15 \mathrm{~min}$ to enable the formation of dissolved Fe-starch complexes. The mixture was purged with nitrogen gas to remove dissolved oxygen. Then the $\mathrm{Fe}^{+2}$ ions were reduced to $\mathrm{Fe}^{0}$ by adding $100 \mathrm{ml}$ of $0.5 \mathrm{M}$ sodium borohydride solution drop-wise into the mixture. After adding the whole borohydride solution, the mixture was stirred for another 30 minutes. Ferrous iron was reduced to zerovalent iron by borohydride according to the following reaction [32].

$$
\begin{aligned}
2 \mathrm{Fe}_{(\mathrm{aq})}^{2+} & +\mathrm{BH}_{4^{-}(\mathrm{aq})}+3 \mathrm{H}_{2} \mathrm{O}_{(1)} \rightarrow 2 \mathrm{Fe}_{(\mathrm{s})}^{0} \\
& +\mathrm{H}_{2} \mathrm{BO}_{3^{-}}(\mathrm{aq}) \\
& 4 \mathrm{H}^{+}{ }_{(\mathrm{aq})}+2 \mathrm{H}_{2(\mathrm{~g})}
\end{aligned}
$$

The product was an aqueous black suspension that iron nanoparticles were separated by centrifuge at $5000 \mathrm{rpm}$ for $5 \mathrm{~min}$ and quickly washed three times with absolute ethanol to remove excess borohydrate. Prepared particles were dried under vacuum overnight and then gently crushed into fine powders.

CMC-Stabilized iron nanoparticles were fabricated with the same procedure where $0.2 \% \mathrm{NaCMC}$ served as stabilizer for ZVI nanoparticles.

Finally nonstabilized iron nanoparticles (Bare NZVI) were prepared without stabilizers loading.

\section{Characterization of stabilized nanoparticles}

In this study, the most promising iron nanoparticles form for arsenic removal was selected for characterization study by X-ray diffraction (XRD) method for crystal structure and composition analysis and Scanning electron microscopy (SEM) technique. XRD is a versatile, non-destructive technique that reveals detailed information about the chemical composition and crystallographic structure of natural and manufactured materials and is based on constructive interference of monochromatic X-rays and a crystalline sample [37].

XRD pattern of starch stabilized nanoparticles was obtained using a Siemens D5000 (Germany) diffractometer by Scanning from $20^{\circ}$ to $85^{\circ}(2 \theta)$ with a step time of $0.3 \mathrm{~s}$ and a step of $0.02^{\circ}(2 \theta)$ with monochromatic $\mathrm{Cu}-\mathrm{K}_{\alpha}$ radiation (40KV, $30 \mathrm{~mA}, \lambda=0.15418 \mathrm{~nm}$ ).

The morphological features and surface characteristics of the starch and $\mathrm{CMC}$ stabilized $\mathrm{Fe}^{0}$ nanoparticles were obtained from Scanning electron microscope (SEM) (Hitachi S 4160, 15.0 kV, Japan).

\section{Batch experimental system}

Arsenic removal experiments were carried out using glass Erlenmeyer $250 \mathrm{~mL}$ flasks containing $150 \mathrm{~mL}$ arsenic solution with determinate concentration at room temperature $\left(25 \pm 1^{\circ} \mathrm{C}\right)$. Arsenic solutions with desired concentration were prepared by dilution of the stock solution immediately before use.

At the first stage of study, in order to compare arsenic removal potential of S-nZVI, C-nZVI and Bare-nZVI, in each set of experiments, $0.045 \mathrm{~g}$ freshly papered nanoparticles was kept in contact with $150 \mathrm{~mL}$ arsenic solution of $2 \mathrm{mg} / \mathrm{L}$ concentration. An attempt was made to compare the efficiencies of arsenic removal without $\mathrm{pH}$ control (i.e. at circum-neutral $\mathrm{pH}$ ). The experiment was performed under oxic conditions, whereas the presence of oxygen would help to remove arsenic through oxygen-induced corrosion products of iron [38].

The flasks were shaken with an orbit incubator shaker (Melrose park, ILL, No3595, USA); operated at $200 \mathrm{rpm}$ for time periods up to $120 \mathrm{~min}$. Parallel experiments were conducted in the absence of nanoparticles but under otherwise identical conditions (blank samples). Blank samples showed no significant changes. At certain reaction time intervals, suspensions were withdrawn from the reactors by $5 \mathrm{ml}$ syringe and centrifuged at $3000 \mathrm{rpm}$ for $5 \mathrm{~min}$ and then filtered through $0.22 \mu \mathrm{m}$ syringe filters for analysis.

After selecting the most effective zero-iron nanoparticles form for arsenic uptake, at the next step of the study, kinetic batch experiments were conducted at different initial concentrations of arsenic in the range of $(0.25-10) \mathrm{mg} / \mathrm{L}$ and adsorbent dose of $0.3 \mathrm{~g} / \mathrm{L}$ at the period of 5-150 $\mathrm{min}$ $\left(25 \pm 1^{\circ} \mathrm{C}, 200 \mathrm{rpm}, \mathrm{pH}=7\right)$.

Adsorption isotherms were obtained by equilibrating arsenic solutions of different nanoparticles dose $(100,300,500,1000) \mathrm{mg} / \mathrm{L}$ at $\mathrm{pH}=7$ with an initial arsenic concentration of $2 \mathrm{mg} / \mathrm{L}$ at room temperature.

To study the effect of $\mathrm{pH}$ on removal efficiency, $\mathrm{pH}$ of the arsenic solution was adjusted to values in the range of (3-11) by adding $0.1 \mathrm{M} \mathrm{NaOH}$ (BDH chemicals Co, UK) and/or $\mathrm{HCl}(37 \%$, Merck $\mathrm{Co})$ through a manual syringe injection.

The effects of adsorbent dosage and initial arsenic concentration were investigated.

All samples were analyzed for residual arsenic concentration using graphite furnace atomic absorption spectrometer (GFAAS, Buck Scientific, Inc. 210VGP model, USA). All experiments were performed at least by duplicate and the averages were reported. The analysis was carried out using calibration curves with correlation coefficients $\left(R^{2}\right)$ of 0.999. Standards were re-measured during each set of experiments to assess accuracy and stability 
in measurements and to assurance adequate instrument performance.

\section{Results and discussion}

\section{Characterization results}

Figure 1 shows the XRD spectra of laboratory prepared $\mathrm{Fe}^{0}$ nanoparticles. The characteristic peak at $2 \theta=44.7^{\circ}$ confirmed the presence of zero-valent iron in freshly prepared S-nZVI. The average crystalline size of the nanoparticles was calculated using Debye Scherrer's equation from the width at half maximum $(\beta)$ of the main intense peak (7).

$$
\mathrm{D}=\frac{\mathrm{k} \lambda}{\beta \cos \theta}
$$

Where, $\mathrm{D}$ is the size of the particles, $\mathrm{K}$ the shape factor, about $0.9, \lambda$ is the wave-length of the emitted X-rays $(0.15418 \mathrm{~nm}) ; \beta$ is the full width at half maximum of the corresponding peak of the XRD and $\theta$ the angle of incidence of X-ray beam. From this analysis it was determined that the synthesized nanomaterials had sizes of $10 \mathrm{~nm}$ approximately.

SEM micrographs of S-nZVI at different magnifications are presented in Figure $2 \mathrm{a}$, b. The images reveal that the nanospheral particles of different sizes are not all separated and a fraction of them form nearly dendritic clusters. SEM image of CMC-stabilized iron nanoparticles (Figure 2c, d) is also shown for comparison. It seems that CMC-coated particles are approximately discrete and have a more uniform shape than starch-stabilized particles.

It can be observed that both coated iron nanoparticles have particle size less than $100 \mathrm{~nm}$.

\section{Selection of most effective $\mathrm{Fe}^{0}$ nanoparticles for arsenic removal Comparison of arsenic removal efficiency}

Figure 3 shows the results of batch experiments conducted for comparative evaluation of synthesized materials potential for As (III) and As (V) uptake from aqueous solution respectively. It was observed that stabilized ZVI nanoparticles exhibited greater reactivity and could yield higher removal capacity of both As (III) and As (V) in comparison with non-stabilized nanoparticles. Polymer surface coatings inhibited nZVI aggregation and enhanced their reactivity.

As can be seen S-nZVI samples removed both arsenate and arsenite with higher efficiency and faster rate than that of bare and CMC-stabilized nanoparticles; therefore this form of nanoparticles selected for using in remaining experiments. During the first 5 min of the reaction, $65.4 \%$ of As (III) and $74.6 \%$ of As (V) was removed in the presence of starch stabilized particles while only $17.7 \%$ and $35.6 \%$ of As (III) was removed using bare and CMC-stabilized nanoparticles respectively. In the case of As (V), bare and CMC-coated nanoparticles showed removal efficiency of about 36.6 and $38.2 \%$ at the first 5 min of the reaction respectively.

\section{Arsenic removal mechanism using stabilized nanoparticles}

Carboxcymethyl cellulose is a weak anionic polysaccharide and starch is a natural uncharged polymer. The use of CMC as a stabilizer can accelerate nucleation of Fe atoms during the formation of ZVI nanoparticles and, subsequently, forms a bulky and negatively charged layer via sorption of CMC molecules on the ZVI nanoparticles $[26,39]$ and also according to Lin et al. [40] study, CMC was bound to particle surfaces in the form of bidentate

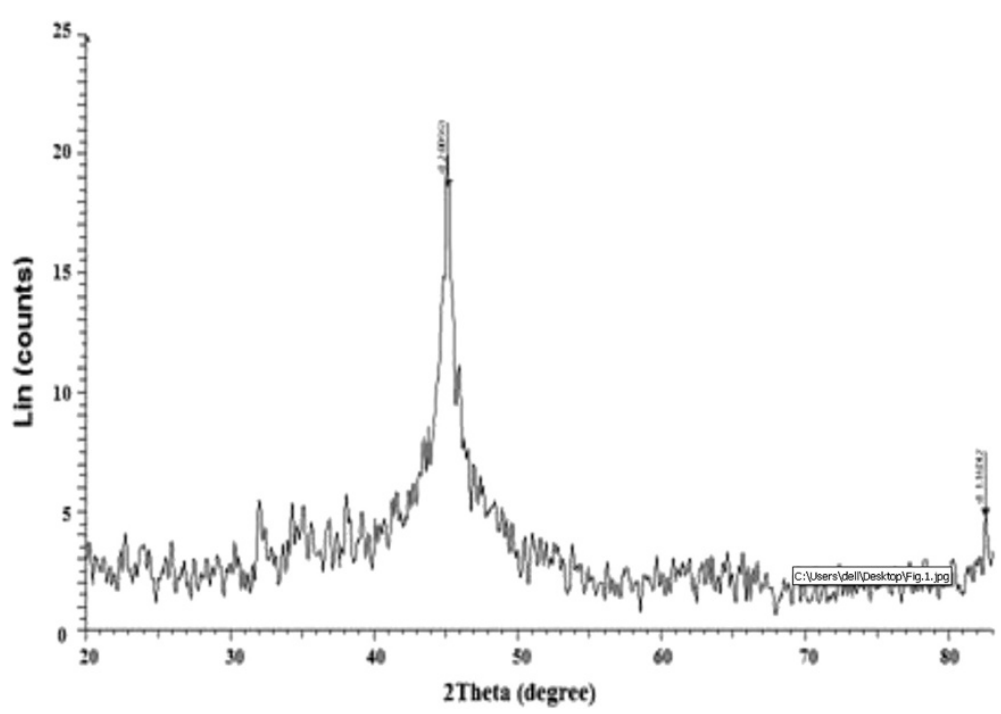

Figure $1 \mathrm{X}$-ray diffraction spectrum of starch stabilized nanoparticles. 

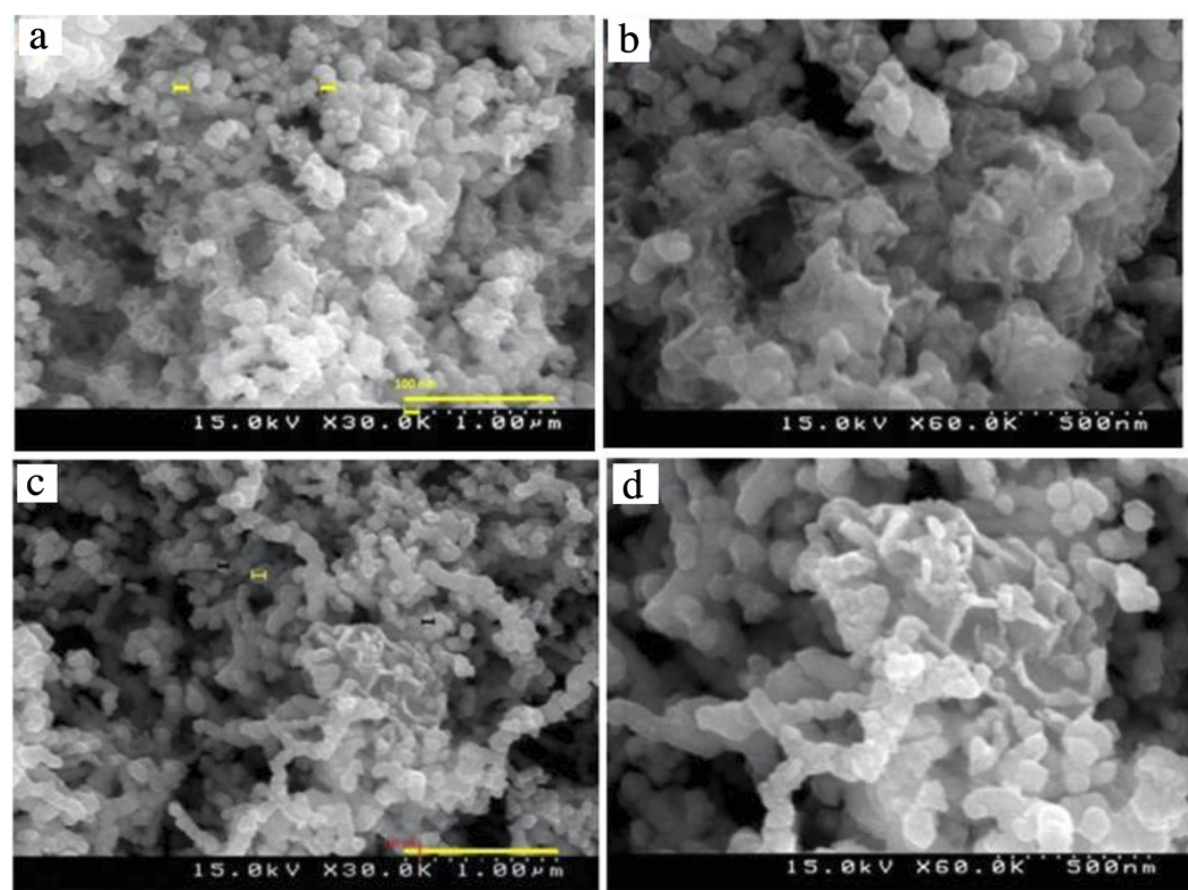

Figure 2 Characteristic SEM images of stabilized nZVI at different magnifications. (a) S-nZVI (30000X); (b) S-nZVI (60000X); (c) C-nZVI (30000X); (d) C-nZVI (60000x).

bridging via the carboxylic group, which could provide both electrostatic and steric repulsion to prevent particle aggregation.

Herein, SEM images show, CMC kept nanoparticles physically separated and led to produce more stable nanoparticles (Figure 2c).

A fraction of the particles cannot be stabilized by any modifier and rapidly agglomerates to micron sized aggregates, as is also observed for unmodified NZVI. This nondispersible fraction is attributed to strong magnetic attractions among the larger particles present in the polydispersed NZVI slurry as the magnetic attractive forces increase [39].

Starch-stabilized particles are not all separated (referring to SEM image in Figure 2).

Nonetheless based on the aforementioned facts, starch stabilized nanoparticles had superior removal ability toward arsenic and displayed $\sim 36.5 \%$ greater removal for As (V) and $30 \%$ for As (III) in comparison with C-nZVI.

The presumable explanation for this phenomenon is attribute to predominant removal mechanisms for arsenic remediation by NZVI which appear to be adsorption and/or surface precipitation, followed by redox reaction $[41,42]$. Coating the nanoparticles with the stabilizers greatly alters the surface potential, which can also affects sorption of the arsenic species [43]. The starch is a neutral polymer and stabilizes nanoparticles through steric repulsion arising from the osmotic force when the starch layers overlap as the particles collide. In fact, starch bridging prevents the nanoparticles from intense aggregating, and thus, maintains their high sorption capacity [19].

Since the predominant forms of As in natural groundand surface waters (neutral $\mathrm{pH}$ like our experimental $\mathrm{pH}$ conditions) are arsenate (As (V), as oxyanions $\mathrm{H}_{2} \mathrm{AsO}_{4}^{-}$and $\mathrm{HAsO}_{4}^{2-}$ ) and arsenite (As (III), as the neutral $\mathrm{H}_{3} \mathrm{AsO}_{3}^{0}$ species) it might be postulated that the negatively charged layer on C-nZVI particles surface due to electrostatics repulsion do not favor the adsorbing arsenic oxyanions and thus the removal efficiency is reduced while starch as a surface buffer is reduced the effect of $\mathrm{H}^{+} / \mathrm{OH}^{-}$on the surface charge of S-nZVI particles and therefore this type of stabilized $\mathrm{Fe}^{0}$ nanoparticles effectively removed arsenic from samples.

Similar result was confirmed in the An and Zhao [43] study in the arsenic immobilization using polysaccharide stabilized Fe-Mn nanoparticles. They also found that from the particle stabilization viewpoint, CMC is likely to be a more effective stabilizer than starch.

According to the results of the first stage of the present study, S-nZVI proved to be an outstanding material from arsenic removal standpoint, however there is a clear trade off to choosing the best stabilized nanoparticles form.

It should be noted that comparison of arsenic removal efficiency by some other nanomaterials shows that starch stabilized nanoparticles are more effective than the others.

Gupta et al. [44] reported that with an initial dose rate of $0.5 \mathrm{~g} / \mathrm{L}$ of Chitosan zerovalent iron nanoparticles, 


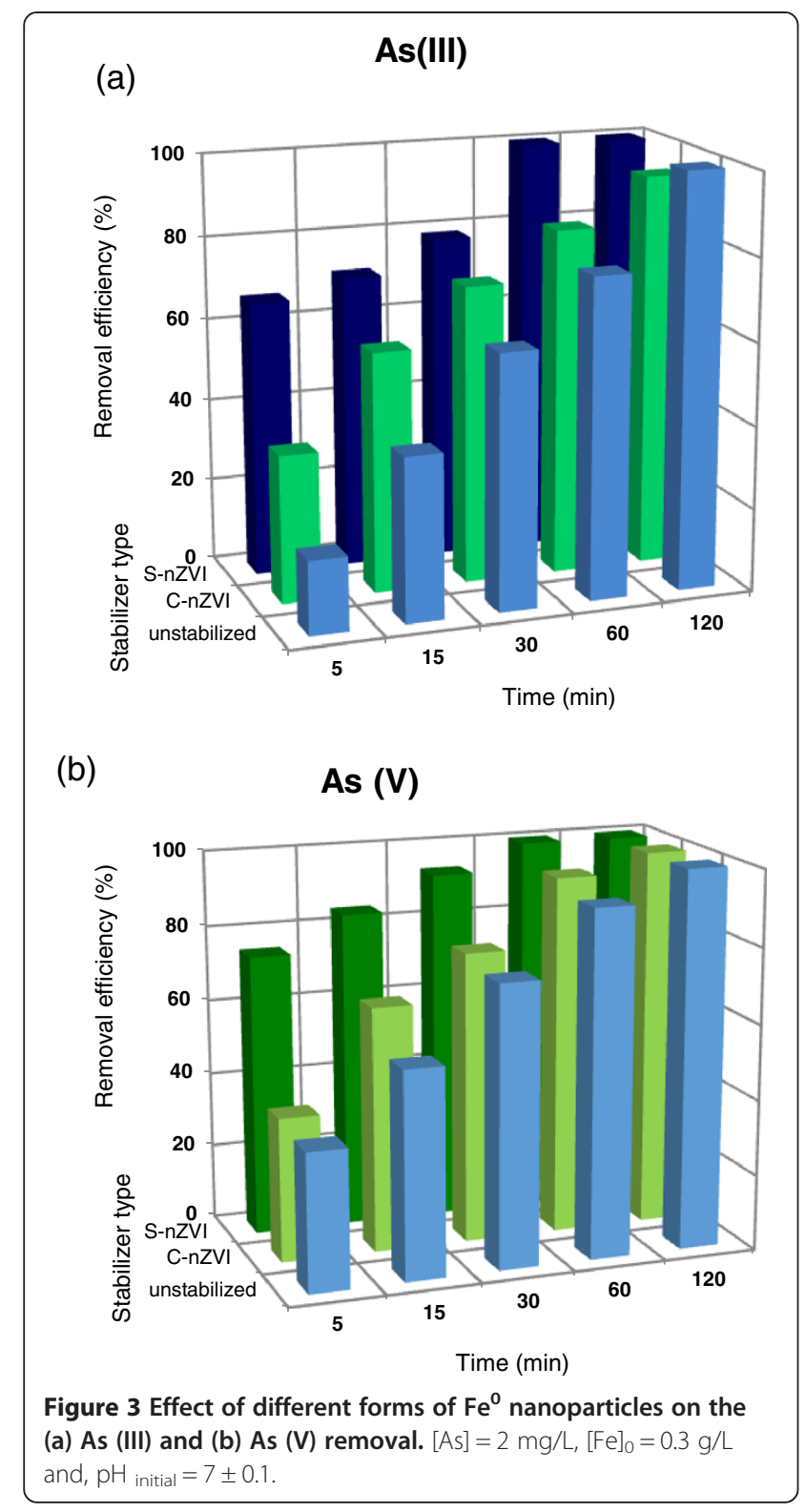

concentrations of As (III) and As (V) were reduced from $2 \mathrm{mg} / \mathrm{L}$ to $<5 \mu \mathrm{g} / \mathrm{L}$, in less than $180 \mathrm{~min}$, while in this study, almost complete removal of As (III) and As (V) ( $2 \mathrm{mg} / \mathrm{L}$ initial concentration) was achieved in less than $120 \mathrm{~min}$ when the starch zero-valent iron nanoparticles mass concentration was $0.3 \mathrm{~g} / \mathrm{L}$.

Shipley et al. [45] used magnetite nanoparticles for the removal of As and reported that magnetite nanoparticles at $0.5 \mathrm{~g} / \mathrm{L}$ adsorbed $92.6 \mu \mathrm{g} / \mathrm{L}$ arsenate and $93.9 \mu \mathrm{g} / \mathrm{L}$ arsenite from an initial concentration of $100 \mu \mathrm{g} / \mathrm{L}$ in $1 \mathrm{~h}$. Based on our observations in the next experimental phase, with material loading at $0.3 \mathrm{~g} / \mathrm{L}$ and $\mathrm{pH}=7$, all the arsenic contamination (up to $500 \mu \mathrm{g} / \mathrm{L}$ ) could be removed and the arsenic residual concentration could drop to zero in just $5 \mathrm{~min}$.
After treatment in the conditions mentioned above, the soluble iron concentration that determines the amounts of iron ion leaching from S-nZVI was analyzed in filtrate supernatant fluid which was below the admissible limit set by the Institute of Standard and Industrial Research of Iran $(0.3 \mathrm{mg} / \mathrm{L})$. Nonetheless the iron concentration may be influenced by operating conditions such as $\mathrm{pH}$, dissolved oxygen concentration and the presence of arsenic species.

\section{Kinetic study}

Adsorption process on S-nZVI surface was very rapid and the time required to reach sorption equilibrium was $2 \mathrm{~h}$ for all concentrations of arsenic. Figure 4 shows the adsorption percentage of As (V) and As (III) on the Starched $\mathrm{Fe}^{\mathrm{O}}$ nanoparticles.

The experimental data best fitted the pseudo-secondorder kinetic model and the adsorption process might be chemisorptions which is suitable for sorption at low initial concentrations [46].

The linear equation of the pseudo-second-order model can be expressed as:

$$
\frac{t}{q_{t}}=\frac{1}{k_{2} q_{e}{ }^{2}}+\frac{t}{\mathrm{q}_{e}}
$$

Where $\mathrm{q}_{\mathrm{e}}$ and $\mathrm{q}_{\mathrm{t}}(\mathrm{mg} / \mathrm{g})$ are the amount of adsorbed arsenic at equilibrium and at time $\mathrm{t}(\mathrm{min})$, respectively. The

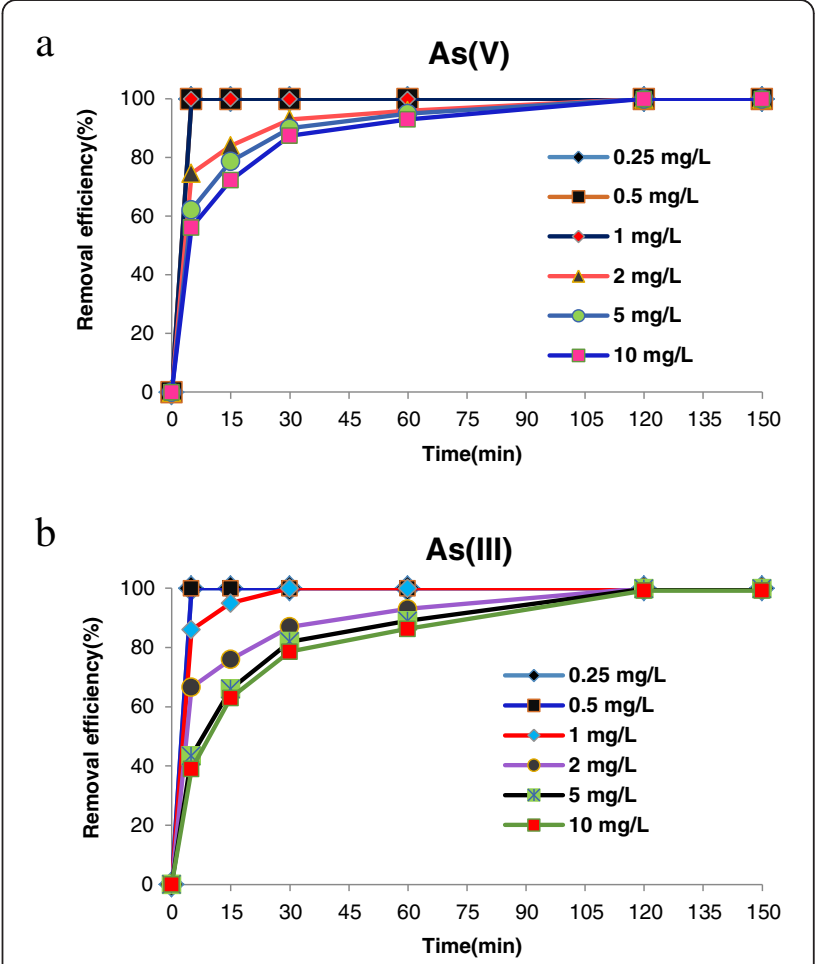

Figure 4 Adsorption kinetics of As (V), (III) by S-nZVI (a, b). Adsorbent dosage $=0.3 \mathrm{~g} / \mathrm{L}, \mathrm{pH}=7$. 
Table 1 Kinetic model parameters of pseudo second-order

\begin{tabular}{|c|c|c|c|c|}
\hline $\mathrm{R}^{2}$ & $\begin{array}{l}\text { Parameters } \\
\mathrm{k}(\mathrm{g} /(\mathrm{mg} \cdot \mathrm{min}))\end{array}$ & $q_{e}(\mathrm{mg} / \mathrm{g})$ & Initial Cons.(mg/L) & $\begin{array}{l}\text { Arsenic } \\
\text { species }\end{array}$ \\
\hline 0.9992 & 0.089 & 6.75 & 2 & \\
\hline 0.9994 & 0.03 & 16.94 & 5 & $\mathrm{As}(\mathrm{V})$ \\
\hline 0.9977 & 0.0077 & 34.12 & 10 & \\
\hline 0.9985 & 0.024 & 6.66 & 2 & \\
\hline 0.9986 & 0.0074 & 17.8 & 5 & $\mathrm{As}(I I I)$ \\
\hline 0.9996 & 0.0055 & 31 & 10 & \\
\hline
\end{tabular}

results are presented in Table 1 however the adsorption data for As (III) and As (V) at an initial concentrations of $0.25,0.5,1 \mathrm{mg} / \mathrm{L}$ were not used in the fitting because all arsenic species were removed and the $\mathrm{q}_{\mathrm{e}}$ value could not be determined.

\section{Adsorption isotherms}

The Langmuir and Freundlich equations are common isotherm models for single-solute adsorption which were tested with equilibrium data. The linear forms of the two models are:

$$
\begin{aligned}
& \text { Langmuir: } \frac{\mathrm{C}_{\mathrm{e}}}{\mathrm{q}_{e}}=\frac{C_{e}}{\mathrm{q}_{\max }}+\frac{1}{\mathrm{q}_{\max } \mathrm{K}_{\mathrm{L}}} \\
& \text { Freundlich: } \log \mathrm{q}_{\mathrm{e}}=\log \mathrm{K}_{\mathrm{F}}+\frac{1}{\mathrm{n}} \log \mathrm{C}_{\mathrm{e}}
\end{aligned}
$$

Where, $\mathrm{q}_{\mathrm{e}}(\mathrm{mg} / \mathrm{g})$ and $\mathrm{C}_{\mathrm{e}}(\mathrm{mg} / \mathrm{L})$ are equilibrium adsorption capacity and equilibrium arsenic concentration on the adsorbent and in the solution, respectively, $\mathrm{q}_{\max }$ $(\mathrm{mg} / \mathrm{g})$ is the monolayer adsorption capacity; $\mathrm{K}_{\mathrm{L}}(\mathrm{L} / \mathrm{mg})$ is Langmuir adsorption constant related to the free energy of adsorption. $\mathrm{K}_{\mathrm{F}}(\mathrm{mg} / \mathrm{g})(\mathrm{mg} / \mathrm{L})^{-1 / \mathrm{n}}$ and $\mathrm{n}$ (dimensionless) are constants related to the adsorption capacity and affinity, respectively. Calculated isotherm parameters related to the models using linear regression analysis for As (III) and As (V) adsorption are shown in Table 2.

The results confirmed that the Langmuir isotherm model is the highest fitted model for the adsorption process of both As (III) $\left(\mathrm{q}_{\max }=14 \mathrm{mg} / \mathrm{g}\right)$, As $(\mathrm{V})\left(\mathrm{q}_{\max }=12.2 \mathrm{mg} / \mathrm{g}\right)$. This implies that arsenic adsorption on S-nZVI is monolayer. Furthermore, the values of $\mathrm{R}_{\mathrm{L}}$ for the Langmuir isotherm were between 0 and 1 , and the Freundlich constant $1 / \mathrm{n}$ was smaller than 1 (As(V) 0.46 and As(III) 0.57), indicating a favorable process. The fundamental properties of the Langmuir isotherm can be explained in terms of dimensionless separation factor $\mathrm{R}_{\mathrm{L}}:\left(\mathrm{R}_{\mathrm{L}}=1 /\left(1+\mathrm{k}_{\mathrm{L}} \cdot \mathrm{C}_{0}\right)\right)$.

\section{Effect of initial arsenic concentration and nanoparticles dose} The laboratory results on the effects of initial arsenic concentration in removing arsenic from water are indicated in Figure 5.
Arsenic species could be removed using S-nZVI in a short time. for example, when the initial concentration was less than $1 \mathrm{mg} / \mathrm{L}$, the removal fraction of both arsenite and arsenate was more than $99 \%$ and there was very little arsenic left in the solution after only $30 \mathrm{~min}$ treatment however with increasing initial concentration of contaminants, the removal efficiency decreases. It is clear that for lower initial concentrations of arsenic, adsorption was very fast.

For high arsenite concentration of $10 \mathrm{mg} / \mathrm{L}$, the residual concentration in the solution was reduced to about $1.4 \mathrm{mg} / \mathrm{L}$ after $60 \mathrm{~min}$ (Figure 4b). When initial concentration increase, only a fewer active sites for adsorption of arsenic remain on NZVI and the removal percentage is reduced.

This result has been confirmed by Khodabakhshi et al. [47] which reported As (III) removal with magnetite nanoparticles is inversely related to initial arsenic concentrations.

Figure 6 demonstrates the variation in As (III), (V) removal in water samples as a function of S-nZVI concentrations in solution.

It is clear, the percentage removal of As (V) is more than As (III) over the range of nano particle concentrations and the removal of both arsenite and arsenate increased from $\sim 44 \%$ and $\sim 60 \%$ to more than $95 \%$ when the dose of S-nZVI applied increased from 0.1 to $1 \mathrm{~g} / \mathrm{L}$ over a $30 \mathrm{~min}$ period. This is accordance with the fact that the adsorptive and active sites available for a fixed concentration of arsenic on the nanoparticles surface increased when the nanoparticles loading increased.

A similar dose dependency trend in arsenic removal using magnetite [45], goethite [48] and ultrafine iron oxide $\left(\alpha-\mathrm{Fe}_{2} \mathrm{O}_{3}\right)$ nanoparticles [49] has been reported in the literature.

\section{Effect of $\mathrm{pH}$}

The percentage removal of arsenic species using starch stabilized $\mathrm{Fe}^{0}$ nanoparticles as a function of $\mathrm{pH}$ is separately presented in Figure 7.

The removal of both As (III) and As (V) species was found to be optimum at $\mathrm{pH}$ range of 5-7 and displayed a maximum uptake at around $\mathrm{pH} 5$ with the amount of 77.26 and $100 \%$ respectively. The removal efficiency of arsenite was declined to approximately $30 \%$ and $18 \%$ and the arsenate removal to approximately $48 \%$ and $20 \%$ in solution during the first $5 \mathrm{~min}$ of the reaction, by changing $\mathrm{pH}$ to 9 and 11 respectively.

This phenomenon can be elucidated from speciation of arsenic in solution. The dissociation constants of aqueous $\mathrm{As}(\mathrm{III})$ are $\mathrm{pK}_{\mathrm{a} 1}=9.17, \mathrm{pK}_{\mathrm{a} 2}=12.1$ and $\mathrm{pK}_{\mathrm{a} 3}=13.4$. When the $\mathrm{pH}$ is above 9.17, anionic $\mathrm{H}_{2} \mathrm{AsO}_{3}^{-}$is mainly $\mathrm{As}$ (III) species and the predominant species at $\mathrm{pH}$ below 9.17 is neutral, namely $\mathrm{H}_{3} \mathrm{AsO}_{3}$. $\mathrm{As}(\mathrm{V})$ predominantly 
Table 2 Adsorption isotherm parameters for arsenic removal by S-nZVI

\begin{tabular}{llllllll}
\hline $\mathbf{R}^{\mathbf{2}}$ & $\begin{array}{l}\text { Freundlich model } \\
\mathbf{n}\end{array}$ & $\mathbf{K}_{\mathbf{F}}(\mathbf{m g} / \mathbf{g})(\mathbf{m g} / \mathbf{L})^{-\mathbf{1} / \mathbf{n}}$ & $\mathbf{R}_{\mathbf{L}}$ & $\mathbf{R}^{\mathbf{2}}$ & $\begin{array}{l}\text { Langmuir model } \\
\mathbf{K}_{\mathbf{L}}(\mathbf{L} / \mathbf{m g})\end{array}$ & $\mathbf{q}_{\mathbf{m}}(\mathbf{m g} / \mathbf{g})$ & Arsenic species \\
\hline 0.9575 & 2.17 & 14.36 & 0.06 & 0.9927 & 7.6 & 14 & $\mathrm{As}(\mathrm{V})$ \\
0.9487 & 1.74 & 9.36 & 0.16 & 0.9935 & 2.48 & 12.21 & $\mathrm{As}(I I I)$ \\
\hline
\end{tabular}

$(R L>1)$ : unfavorable adsorption, $(0<R L>1)$ : favorable, $(R L=0)$ : irreversible and linear adsorption $(R L=1)$.

exists as $\mathrm{H}_{2} \mathrm{AsO}_{4}^{-}$and $\mathrm{HAsO}_{4}^{2-}$ in the $\mathrm{pH}$ range of 2.2 to $11.5[50,51]$.

On the other hand, removal of arsenic occurs, predominantly by adsorption on iron oxide species generated by corrosion of zerovalent iron. At $\mathrm{pH}>8$, these iron oxides present in the monomeric anionic form $\mathrm{Fe}(\mathrm{HO})_{4}^{-}$[52] and repel negative charge arsenic species. As a result, the removal of both arsenic species was significantly reduced due to electrostatic repulsion and also competition between $\mathrm{OH}^{-}$and arsenic oxyanions for the active sites on the surface of nanoparticles as well at $\mathrm{pH}$ above 9 .

Ferrous iron $\left(\mathrm{Fe}^{2+}\right)$ is a primary product from metallic iron corrosion process [53] which according to Taha and Ibrahim $\mathrm{pH}$ and $\mathrm{Fe}^{2+}$ has a very strong reverse correlation in NZVI system [54] and in low $\mathrm{pH}$ iron hydroxides are present as cationic monomers of $\mathrm{FeOH}^{+2}$ and $\mathrm{Fe}(\mathrm{OH})_{2}^{+}$ [47], hence arsenic adsorption should be enhanced in acid conditions. Interestingly, our results indicated around $\mathrm{pH} 3$ the arsenic sequestration rate was lower than the maximum rate. Probably the diminished arsenic uptake at $\mathrm{pH}$ below 5 can be attributed to the break-down smaller segments of starch and elevated solution viscosity and also decomposition of $\mathrm{Fe}^{0}$ nanoparticles at $\mathrm{pH}<5$. The study carried out by An et al. [19] shows similar results and they reported that $13 \%$ of starch-bridged magnetite nanoparticles at pH 3.2 was dissolved.

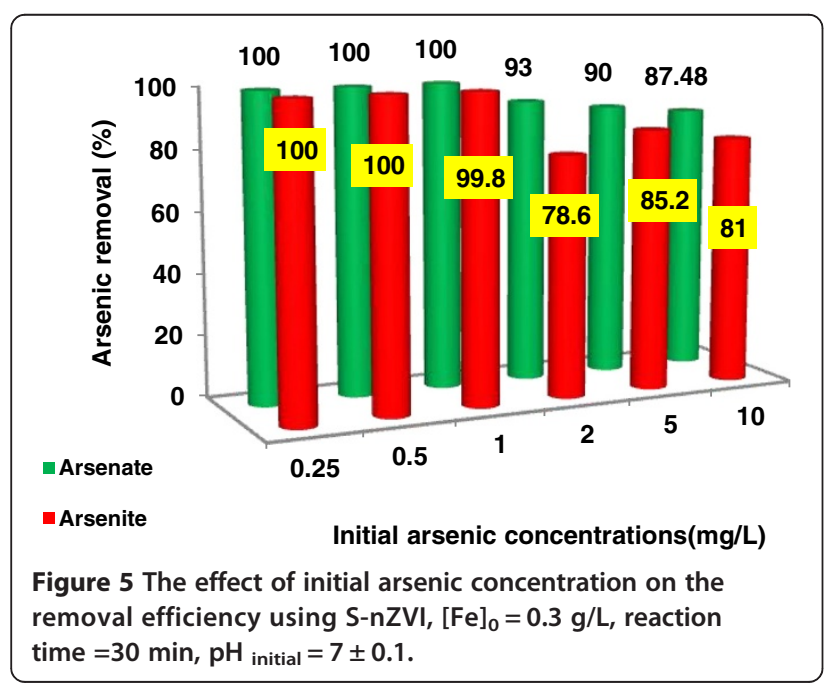

It is evident that S-nZVI is effective in slightly acidic and natural $\mathrm{pH}$ values. Whereas most natural waters are at near neutral conditions, this result is very desirable.

\section{Comparative evaluation of arsenic removal by different adsorbents}

At final stage of the study, the S-nZVI adsorption capacity $\left(\mathrm{q}_{\max }\right)$ has been compared with some reported data for different adsorbents (Table 3). It is evident that Starched $\mathrm{Fe}^{0}$ nanoparticles are relatively good adsorbent and have superior performance in removing both $\mathrm{As}(\mathrm{III})$ and $\mathrm{As}(\mathrm{V})$ from aqueous solutions in a short time. Hence, they should be subsequently confirmed on real contaminated water bodies. Future research could focus on the effect of various diverse ions/competing co-ions upon adsorption of arsenic and the reusability of nanoparticles.

It should be noted that Nano zero-valent iron is the cheapest among other nanomaterials such as $\mathrm{Nano}_{\mathrm{TiO}}$, Nano-Magnetite and Nano Iron-Oxide [60], however depending on the type and amount ordered nZVI, it costs in the range of $£ 50-150$ per $\mathrm{kg}$. In order to compete against existing treatment methods, the price of nZVI must reduce to approximately $<£ 10$ per $\mathrm{kg}$ [53]. In spite of this barrier, their use is likely to increase at the point-of-use/entry scale.

\section{Conclusion}

In this work, starch was proven to be an effective stabilizer for $\mathrm{Fe}^{0}$ nanoparticles. The starch stabilized nanoparticles demonstrated comparable high removal efficiency towards

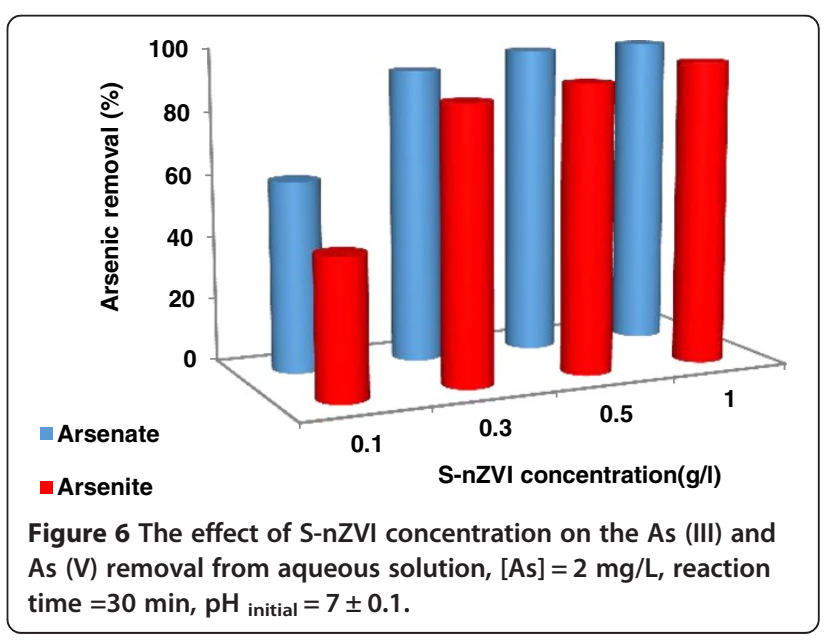



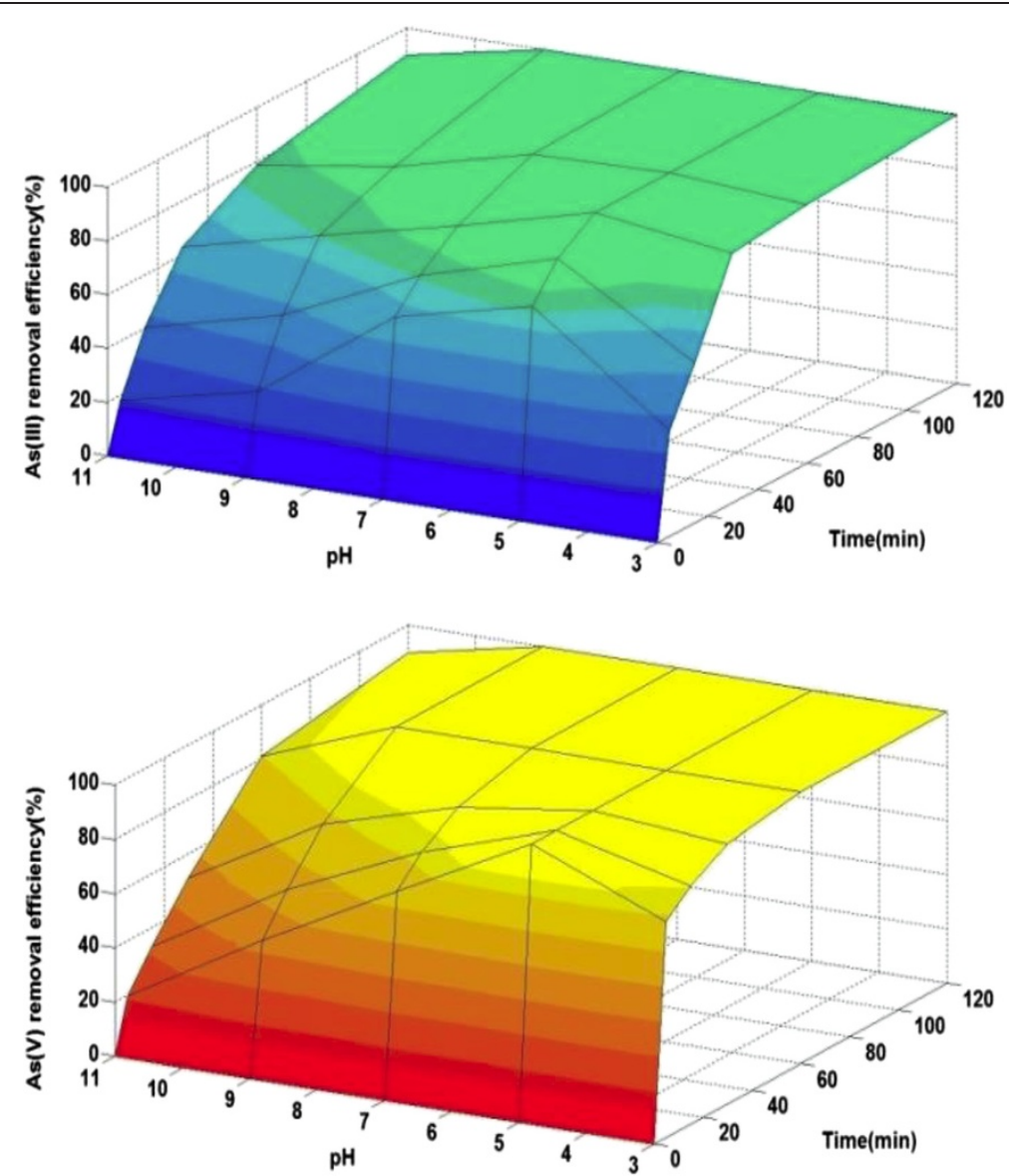

Figure 7 Effect of $\mathrm{pH}$ on the As (III) and As (V) removal efficiency using S-nZVI, $[\mathrm{As}]=2 \mathrm{mg} / \mathrm{L},[\mathrm{Fe}]_{0}=0.3 \mathrm{~g} / \mathrm{L}$.

arsenic species without the need of pre-oxidation and/or pH adjustment.

As a common trend, it was observed that an increase of S-nZVI loading and contact time and a decrease of $\mathrm{pH}$ and initial arsenic concentration determined a higher efficiency of arsenic removal. The optimum removal efficiency of both arsenite and arsenate was found at $\mathrm{pH}$ range of 5-7.

As (V) removal was faster than As (III) and both species removal increased with S-nZVI mass (0.1-1 g/L) attaining more than $95 \%$ after $30 \mathrm{~min}$ of time contact with the $0.3 \mathrm{~g} / \mathrm{L}$ nanoparticles concentration.

Table 3 Comparison of adsorption capacity for arsenic with various nanoadsorbents

\begin{tabular}{|c|c|c|c|c|c|}
\hline \multirow[b]{2}{*}{ Adsorben } & \multirow[b]{2}{*}{ Ads. capacity (mg/g) } & \multirow[b]{2}{*}{$\mathrm{pH}$} & \multicolumn{2}{|l|}{ Experimental conditions } & \multirow[b]{2}{*}{ Reference } \\
\hline & & & Concentrations (mg/L) & Arsenic species & \\
\hline $\mathrm{Fe}_{2} \mathrm{O}_{3}$ & 4.6 & 7 & $1-4$ & $\mathrm{As}(\mathrm{V})$ & {$[55]$} \\
\hline $\mathrm{Fe}_{3} \mathrm{O}_{4}$ & 0.2 & 9 & $0.1-2$ & $A s(V)$ & {$[56]$} \\
\hline $\mathrm{a}-\mathrm{FeOOH}$ & 76.3 & 3 & $5-500$ & $A s(V)$ & [48] \\
\hline \multirow[t]{2}{*}{$\mathrm{Fe}_{3} \mathrm{O}_{4}-\mathrm{\gamma} \mathrm{Fe}_{2} \mathrm{O}_{3}$} & 4.85 & 6.5 & 2 & $A s(V)$ & {$[57]$} \\
\hline & 4.75 & 6.5 & 2 & $\mathrm{As}(I I I)$ & \\
\hline Crystalline $\mathrm{TiO}_{2}$ & 37.5 & 7 & - & $A s(V)$ & {$[58]$} \\
\hline CuO nanoparticles & 1.068 & 7 & $0.5-1$ & $\operatorname{As}(I I I)$ & [59] \\
\hline \multirow[t]{2}{*}{ Chitosan nZVI } & 119 & 7 & $1-60$ & $\mathrm{As}(\mathrm{V})$ & {$[58]$} \\
\hline & 94 & 7 & $1-60$ & $\mathrm{As}(I I I)$ & {$[59]$} \\
\hline \multirow[t]{2}{*}{ Amorphous $\mathrm{ZrO}_{2}$ nanoparticles } & 32.4 & 7 & $1-60$ & $A s(V)$ & {$[44]$} \\
\hline & 83 & 7 & $0.3-100$ & $\mathrm{As}(I I I)$ & [46] \\
\hline
\end{tabular}


Overall, starch as a low-cost and green stabilizer could be a suitable candidate to enhance iron nanoparticles reactivity for the removal of arsenic contamination from aqueous solutions.

\section{Competing interests}

The authors declare that they have no competing interests.

\section{Authors' contributions}

This study is a part of MSc. approved thesis. The study was directed by MM who is the first author and supervised all the experiments and edited the manuscript. SN (Corresponding author) performed all the experiments and drafted the manuscript. AKh advised the experimental methods. $\mathrm{SN}$ read and approved the final manuscript. ASH was involved in discussion of the results. All authors have read and approved the final manuscript.

\section{Acknowledgement}

The authors appreciate the support provided by Center for Water Quality Research, Institute for Environmental Research of Tehran University of Medical Sciences, Tabriz University of Medical Sciences and Iranian Nano Technology Initiative Council.

\section{Author details}

'Department of Environmental Health Engineering, Tabriz Health Services Management Research Center, Tabriz University of Medical Sciences, Tabriz, Iran. ${ }^{2}$ Center for Water Quality Research (CWQR), Institute for Environmental Research (IER) and department of Environmental Health Engineering, Tehran University of Medical Sciences, Tehran, Iran. ${ }^{3}$ Department of Environmental Health Engineering, School of Health, Center of Student Researches, Tabriz University of Medical Sciences, Tabriz, Iran. ${ }^{4}$ Research Laboratory of Advanced Water and Wastewater Treatment Processes, Department of Applied Chemistry, Faculty of Chemistry, University of Tabriz, Tabriz, Iran. ${ }^{5}$ Department of Environmental Health Engineering, School of Health, Tabriz University of Medical Sciences, Tabriz, Iran.

\section{Received: 18 September 2013 Accepted: 16 April 2014}

Published: 24 April 2014

\section{References}

1. Ravenscroft P, Brammer H, Richards K: Arsenic Pollution: A Global Synthesis. John Wiley\& sons; 2009.

2. Bhattacharya P, Welch A, Stollenwerk K, McLaughlin M, Bundschuh J Panaullah G: Arsenic in the environment: biology and chemistry. Sci Total Environ 2007, 379:109-120

3. Choong T, Chuah TG, Robiah Y, Koay G, Azni I: Arsenic toxicity, health, hazards and removal techniques from water: an overview. Desalination 2007, 217:139-166.

4. Mohan D, Pittman CU Jr: Arsenic removal from water/wastewater using adsorbents-A critical review. J Hazard Mat 2007, 142:1-53.

5. Sharma VK, Sohn M: Aquatic arsenic: toxicity, speciation, transformations, and remediation. A review. Environ Int 2009, 35:743-759.

6. Dastgiri S, Mosaferi M, Fiz M, Olfati N, Zolali S, Pouladi N, Azarfam P: Arsenic exposure, dermatological lesions, hypertension, and chromosomal abnormalities among people in a rural community of Northwest Iran. J Health Popul Nutr 2010, 28(1):1-9.

7. Luther S, Borgfeld N, Kim J, Parsons JP: Removal of arsenic from aqueous solution: a study of the effects of $\mathrm{pH}$ and interfering ions using iron oxide nanomaterials. Microchem J 2012, 101:30-36.

8. WHO: Guidelines for Drinking-Water Quality, third edition, Recommendations. Geneva: World Health Organization; 2011.

9. Mosaferi M, Yunesian M, Dastgiri S, Mesdaghinia A, Esmailnasab N: Prevalence of skin lesions and exposure to arsenic in drinking water in Iran. Sci Total Environ 2008, 390:69-76.

10. Mosaferi M, Taghipour H, Hassani AM, Borghei M, Kamali Z, Ghadirzadeh A Study of arsenic presence in drinking water sources: a case study. Iran J Health Environ 2008, 1(1):19-28 (In Persian).

11. Ghassemzadeh F, Arab Z, Mohhamad H, McLennan G: Arsenic and Antimony in drinking water in Kohsorkh area, Northeast Iran possible risks for the public health. J Applied Sci 2006, 6(13):2705-2714.
12. ISIRI: Drinking Water-Physical and Chemical Specifications. 5th edition. Iran: Institute of Standards and Industrial Research; 2009. In Persian.

13. Mishra AK, Ramaprabhu S: Functionalized graphene sheets for arsenic removal and desalination of sea water. Desalination 2011, 282:39-45.

14. TriszCZ JM, Porta A, Einschlag FSG: Effect of operating conditions on iron corrosion rates in zero-valent iron systems for arsenic removal. Chem Eng J 2009, 150:431-439.

15. Song S, Lopez-Valdivieso A, Hernandez-Campos DJ, Peng C, Monroy-Fernandez MG, Razo-Soto I: Arsenic removal from high-arsenic water by enhanced coagulation with ferric ions and coarse calcite. Water Res 2006, 40:364-472

16. Kumar PR, Chaudhari S, Khilar KC, Mahajan SP: Removal of arsenic from water by electrocoagulation. Chemosphere 2004, 55:1245-1252.

17. Daus $B$, Wennrich $R$, Weiss $H$ : Sorption materials for arsenic removal from water: a comparative study. Water Res 2004, 38(12):2948-2954.

18. Singh TS, Pant KK: Equilibrium, kinetics and thermodynamic studies for adsorption of As(III) on activated alumina. Sep Purif Technol 2004, 36(2):139-147.

19. An B, Liang $Q$, Zhao D: Removal of arsenic(V) from spent ion exchange brine using a new class of starch-bridged magnetite nanoparticles. Water Res 2011, 45:1961-1972.

20. Shih MC: An overview of arsenic removal by pressure-driven membrane processes. Desalination 2005, 172(1):85-97.

21. Ning RY: Arsenic removal by reverse osmosis. Desalination 2002, 143:237-241.

22. Katsoyiannis IA, Zouboulis Al: Application of biological processes for the removal of arsenic from groundwaters. Water Res 2004, 38:17-26.

23. Olyaie E, Banejad H, Afkhami A, Rahmani A, Khodaveisi J: Development of a cost-effective technique to remove the arsenic contamination from aqueous solutions by calcium peroxide nanoparticles. Sep Purif Technol 2012, 95:10-15.

24. Morgada ME, Levy IK, Salomone V, Farias SS, Lo'pez G, Litter MI: Arsenic (V) removal with nanoparticulate zerovalent iron: Effect of UV light and humic acids. Catal Today 2009, 143:261-268.

25. Rahmani AR, Ghaffari HR, Samadi MT: A comparative study on arsenic (III) removal from aqueous solution using nano and micro sized zero valent iron. Iran J Environ Health Sci Eng 2011, 8(2):175-180.

26. He F, Zhao D: Manipulating the size and dispersibility of zerovalent iron nanoparticles by use of carboxymethyl cellulose stabilizers. Environ Sci Technol 2007, 41:6216-6221.

27. He F, Zhao D, Paul C: Field assessment of carboxymethyl cellulose stabilized iron nanoparticles for in situ destruction of chlorinated solvents in source zones. Water Res 2010, 44:2360-2370.

28. Dickson D, Liu G, Li C, Tachiev G, Cai Y: Dispersion and stability of bare hematite nanoparticles: effect of dispersion tools, nanoparticle concentration, humic acid and ionic strength. Sci Total Environ 2012, 419:170-177.

29. Sun $Y P$, Li XQ, Zhang $W X$, Wang $H$ : A method for the preparation of stable dispersion of zero-valent iron nanoparticles. Colloids Surf 2007, 308:60-66.

30. Raychoudhury T, Naja G, Ghoshal S: Assessment of transport of two polyelectrolyte-stabilized zero-valent iron nanoparticles in porous media. J Contam Hydrol 2010, 118:143-151

31. Cao J, Xu C, Tang H, Tang S, Cao M: Synthesis of monodispersed CMC-stabilized Fe-Cu bimetal nanoparticles for in situ reductive dechlorination of 1, 2, 4 trichlorobenzene. Sci Total Environ 2011, 409:2336-2341.

32. Alidokht L, Khataee AR, Reyhanitabar A, Oustan S: Reductive removal of $\mathrm{Cr}$ (VI) by starch-stabilized Fe0 nanoparticles in aqueous solution. Desalination 2011, 270:105-110.

33. Wang Q, Qian H, Yang Y, Zhang Z, Naman C, Xu X: Reduction of hexavalent chromium by carboxymethyl cellulose-stabilized zero-valent iron nanoparticles. J Contam Hydrol 2010, 114:35-42.

34. Xu Y, Zhao D: Reductive immobilization of chromate in water and soil using stabilized iron nanoparticles. Water Res 2007, 41:2101-2108.

35. Lein HL, Elliott DW, Sun YP, Zhan WX: Recent progress in zero-valent iron nanoparticles for groundwater remediation. J Environ Eng Manag 2006, 16:371-380.

36. Choi HC, Giasuddin AM, Kanel S: Method of synthesizing air-stable zero valent iron nanoparticles at room temperature and applications. US Patent 2008, 11:889-896.

37. Kumar PR: Development and potential applications of nanomaterials for arsenic removal from contaminated groundwater. TRITA LWR Degree Project 2011, 11:07.

38. Tanboonchuy V, Hsu JC, Grisdanurak N, Liao CH: Impact of selected solution factors on arsenate and arsenite removal by nanoiron particles. Environ Sci Pollut Res 2011, 18:857-864. 
39. Cook SM: Assessing the Use and Application of Zero-Valent Iron Nanoparticle Technology for Remediation at Contaminated Sites. Washington, DC: U.S. Environmental Protection Agency; 2009.

40. Lin YH, Tseng HH, Wey MY, Lin MD: Characteristics of two types of stabilized nano zero-valent iron and transport in porous media. Sci Total Environ 2010, 408:2260-2667.

41. Kanel SR, Greneche JM, Choi H: Arsenic(V) removal from groundwater using nano scale zero-valent iron as a colloidal reactive barrier material. Environ Sci Technol 2006, 40:2045-2050.

42. Dong H, Guan X, Lo MC I: Fate of As(V)-treated nano zero-valent iron: determination of arsenic desorption potential under varying environmental conditions by phosphate extraction. Water Res 2012, 46:4071-4080.

43. An B, Zhao D: Immobilization of $A s(I I I)$ in soil and groundwater using a new class of polysaccharide stabilized Fe-Mn oxide nanoparticles. J Hazard Mater 2012, 211-212:332-341.

44. Gupta A, Yunus M, Sankararamakrishnan N: Zerovalent iron encapsulated chitosan nanospheres-A novel adsorbent for the removal of total inorganic Arsenic from aqueous systems. Chemosphere 2012, 86:150-155.

45. Shipley H, Yean S, Kan AT, Tomson MB: Effect of solid concentration, pH, IS, and temperature on arsenic adsorption. Environ Toxicol Chem 2009, 28:509-515.

46. Cui H, Qi L, Gao S, Shang J: Strong adsorption of arsenic species by amorphous zirconium oxide nanoparticles. J Ind Eng Chem 2012, 18:1418-1427.

47. Khodabakhshi A, Amin MM, Mozaffari M: Synthesis of magnetite nanoparticles and evaluation of its efficiency for arsenic removal from simulated industrial wastewater. Iran J Environ Health Sci Eng 2011, 8(3):189-200.

48. Ghosh M, Poinern G, Issa T, Singh P: Arsenic adsorption on goethite nanoparticles produced through hydrazine sulfate assisted synthesis method. Korean J Chem Eng 2012, 29(1):95-102.

49. Tang W, Li Q, Gao S, Shanga J: Arsenic (III, V) removal from aqueous solution by ultrafine a-Fe2O3 nanoparticles synthesized from solvent thermal method. J Hazard Mater 2011, 192:131-138.

50. Wang C, Luo H, Zhang Z, Wu Y, Zhang J, Chen S: Removal of As(III) and As (V) from aqueous solutions using nanoscale zero valent iron-reduced graphite oxide modified composites. J Hazard Mater 2014, 268:124-131.

51. Couture R, Van Cappellen P: Reassessing the role of sulfur geochemistry on arsenic speciation in reducing environments. J Hazard Mater 2011, 189(3):647-652.

52. Yao S, Liu Z, Shi Z: Arsenic removal from aqueous solutions by adsorption onto iron oxide/activated carbon magnetic composite. J Environ Health Sci Eng 2014, 12:1-8.

53. Crane RA, Scott TB: Nanoscale zero-valent iron: future prospects for an emerging water treatment technology: a review. J Hazard Mater 2012, 211-212:112-125.

54. Taha MR, Ibrahim AH: Characterization of nano zero-valent iron (nZVI) and its application in sono-Fenton process to remove COD in palm oil mill effluent. J Environ Chem Eng 2014, 2:1-8.

55. Park $H$, Myung NV, Jung $H$, Choi $H$ : As(V) remediation using electrochemically synthesized maghemite nanoparticles. J Nanopart Res 2009, 11:1981-1989.

56. Turk T, Alp I, Deveci $\mathrm{H}$ : Adsorption of $\mathrm{As}(\mathrm{V})$ from water using nanomagnetite. J Environ Eng 2010, 136:399-404.

57. Chowdhury SR, Yanful E, Pratt A: Arsenic removal from aqueous solutions by mixed magnetite-maghemite nanoparticles. Environ Earth Sci 2010, DOI 10.1007/s12665-010-0865-z.

58. Pena ME, Korfiatis GP, Patel M, Lippincott L, Meng X: Adsorption of As(V) and As(III) by nanocrystalline titanium dioxide. Water Res 2005, 39:2327-2337.

59. Goswami A, Raulb PK, Purkaita MK: Arsenic adsorption using copper oxide (II) nanoparticles. Chem Eng Res Des 2012, 90(9):1387-1396.

60. Brame J, Li Q, Alvarez P: Nanotechnology enabled water treatment and reuse: emerging opportunities and challenges for developing countries. Trends Food Sci Tech 2011, 22:618-624.

doi:10.1186/2052-336X-12-74

Cite this article as: Mosaferi et al.: Removal of Arsenic (III, V) from aqueous solution by nanoscale zero-valent iron stabilized with starch and carboxymethyl cellulose. Journal of Environmental Health Science \& Engineering 2014 12:74 